\title{
Artigos
}

\section{Formação médica e assistência aos processos de abortamento: a perspectiva de residentes de duas universidades públicas em São Paulo, Brasil}

\begin{abstract}
Medical training and abortion care from the perspective of residents from two public universities in São Paulo, Brazil (abstract: p. 15)

Formación médica y asistencia a los procesos de aborto: la perspectiva de residentes de dos universidades públicas en São Paulo, Brasil (resumen: p. 15)
\end{abstract}

\author{
Rosana Machin ${ }^{(a)}$ \\ <rmachin@usp.br>
}

Márcia Thereza Couto(b)

<marthet@usp.br>

Ana Luísa Smith Rocha(c)

<ana.smith@fm.usp.br> iD

Maria Renata Mencacci Costa(d)

<maria.renata.costa@usp.br> (iD)

\author{
(a,b) Departamento de Medicina \\ Preventiva, Faculdade de Medicina \\ (FM), Universidade de São Paulo \\ (USP). Avenida Doutor Arnaldo, \\ 455, sala 2177, Cerqueira Cesar. \\ São Paulo, SP, Brasil 01246-903. \\ (c,d) Graduanda do Curso de Medicina, \\ Departamento de Medicina \\ Preventiva, FM, USP.
}

O aborto é um importante tema sob a perspectiva da saúde pública e permeia a prática de diversas especialidades. Enfocamos a assistência a processos de abortamento e sua relação com a formação recebida em Ginecologia e Obstetrícia (GO) e Medicina de Família e Comunidade (MFC) por residentes de duas faculdades públicas paulistas. A pesquisa seguiu a metodologia qualitativa, e a produção dos dados empíricos se norteou pela técnica de entrevista em profundidade (13 residentes). Os residentes em GO relatam pautar-se nas experiências práticas para condução dos casos de abortamento. Os residentes em MFC relatam discussões sobre o tema e suas conexões com questões de gênero. 0 conhecimento clínico, o desenvolvimento de habilidades e técnicas e a maior inserção da abordagem de gênero na formação se revelam fundamentais para o exercício do cuidado integral às mulheres em processo de abortamento.

Palavras-chave: Formação médica. Abortamento. Ginecologia e obstetrícia. Medicina de familia e comunidade. Gênero. 


\section{Introdução}

O abortamento é definido como a interrupção da gravidez ou expulsão do feto da concepção antes que seja viável (22o semana) ou com o produto da concepção pesando menos de quinhentos gramas ou com menos de 16 centímetros $^{1}$, sendo classificado como espontâneo ou provocado. Nesta segunda categoria, aborto induzido ou interrupção voluntária da gravidez são termos correlatos, usados como sinônimos neste trabalho. Além destas somam-se as interrupções de gestações decorrentes de risco de vida para a mãe portadora de patologia grave e em razão de: malformações fetais, as interrupçóes de gravidezes resultantes de violência sexual e os abortos provocados. Como algumas das interrupçôes envolvem ilegalidade e julgamentos de caráter moral, há dificuldade em se dimensionar o fenômeno. $\mathrm{O}$ abortamento inseguro, por sua vez, é definido como procedimento para interromper uma gravidez não desejada realizado por pessoas sem as devidas habilidades ou em ambiente sem os mínimos padróes médicos, ou ambos ${ }^{2}$. Foi estimada a ocorrência global de 56 milhóes de abortamentos induzidos entre 2010 e 2014, sendo 54,9\% destes em situaçóes inseguras. Análise de padróes mundiais demonstrou que, proporcionalmente, o número de abortos induzidos inseguros aumentou de 44\% em 1995 para 49\% em 2008, e que esta taxa foi menor em países com leis liberais em relação ao abortamento. As taxas de abortamento não foram menores em países com legislação restritiva entre 2010-2014³ , mas foi percebido que medidas de planejamento familiar e acesso seguro ao abortamento são essenciais para atingir as metas de desenvolvimento do milênio.

No Brasil, a legislação que trata de aborto induzido data de 1940, e prevê realização de abortamento legal em casos de: risco para a vida da mãe, gravidez decorrente de estupro e, desde 2012, casos de fetos que apresentem anencefalia. Embora haja subnotificação dos casos de abortamento, este é considerado como uma das quatro principais causas de morte materna ${ }^{2}$, e a curetagem manual pós abortamento o terceiro procedimento obstétrico mais realizado no país ${ }^{1}$. Segundo análise sistemática conduzida pela OMS, o abortamento induzido figura como causa relacionada a 7,9\% das causas de mortalidade materna mundial, elevando-se esse percentual para $9,9 \%$ na América Latina e na África ${ }^{2}$.

Houve declínio nas mortes por complicações de abortamento induzido, o que se considera influência de maior uso do medicamento Misoprostol $^{3}$, em relação a métodos caseiros (chás, manipulação uterina perfurante, etc.). Contudo, complicaçôes ainda ocorrem em cerca de 50\% dos casos de aborto medicamentoso, devido, sobretudo, a falta de orientação em relação ao uso do medicamento ou, mesmo, uso de medicamentos inseguros 4 . Mesmo em situações em que as mulheres dispóem de recursos financeiros para proceder abortamentos em clínicas particulares (considerando legislação restritiva), a percepção de maus- tratos e atendimento violento (por vezes, com realização de curetagem sem anestesia) é relatada 5 .

No Brasil, no ano de 2013, registraram-se 205.855 internaçóes decorrentes de abortos, sendo 154.391 por interrupção induzida ${ }^{6}$. Houve, no período de 1995 e 2013, uma diminuição de internação de mulheres de dez a 49 anos por complicaçóes de aborto (redução de 27\%), e a estimativa do número anual de abortos induzidos recuou $26 \%$. Esse fenômeno seria explicado por fatores como: o aumento da escolaridade feminina, a redução da taxa de fecundidade total, a ampliação de cobertura das medidas 
anticoncepcionais e consequência do elevado percentual de mulheres em idade fértil esterilizadas.

A Pesquisa Nacional de Aborto ${ }^{7}$ colaborou na desconstrução do estereótipo da mulher que aborta: constatou-se que, em sua maioria, são mulheres entre vinte e 29 anos, em união estável, com até oito anos de estudo, trabalhadoras e católicas. O abortamento é um evento reprodutivo comum na vida das mulheres brasileiras. Aos quarenta anos, uma em cada cinco mulheres já fez ao menos um aborto. O evento está distribuído: em todas as idades, entre mulheres casadas ou não, em todas as religióes, níveis educacionais, classes sociais, grupos raciais, regióes do país e municípios de tamanhos variados, o que indica uma permanência estrutural e disseminada da prática na vida das mulheres.

Diante deste cenário, a formação de profissionais da saúde solicita atenção especial, seja pela magnitude do fenômeno, à necessidade de habilidades ao cuidado das mulheres em situação de abortamento e as consequências das ocorrências para a saúde sexual, reprodutiva e mental das mulheres. Neste sentido, as Diretrizes Curriculares Nacionais propostas pelo MEC em $2014^{8}$ estabelecem que a formação do profissional médico deve estar em consonância com as diretrizes do Sistema Único de Saúde (SUS) e o quadro epidemiológico vigente. Sendo assim, diante de uma questão de saúde pública de tal magnitude, prevalência e complexidade, é relevante considerar qual a formação que os estudantes de Medicina recebem sobre o tema, no contexto da graduação e nas residências médicas.

Segundo Verdonk et al. ${ }^{9}$ e Bleakley ${ }^{10}$, as questóes de gênero precisam ser abordadas na formação dos futuros médicos e demais profissionais da saúde, especialmente pela maneira como a cultura médica lida com problemas e tratamentos de saúde. Autores como Bickel ${ }^{11} \mathrm{e}$ Verdonk et al. ${ }^{9}$ propóem que escolas de medicina adotem visões mais claras sobre a relevância da perspectiva de gênero na formação de seus alunos. Tomam como exemplo: a abordagem clínica das doenças coronarianas, a farmacologia, temas médico-sociais (como violência doméstica e sexual), tópicos como sexualidade e problemas sexuais, domínios como a saúde mental. Além desta dimensão explícita do conhecimento e manejo clínico referidos, as diferenças de gênero em assuntos como a comunicação e a relação médico-paciente são especialmente relevantes e merecem atenção destacada. Finalmente e igualmente importante, advogam que gênero deve fazer parte da formação em “cuidados primários de saúde” por causa de seu caráter multidisciplinar.

O presente estudo discute como a formação médica, em conjunto com as biografias pessoais, experiências de vida e opinióes, influenciam na prática médica frente ao dilema moral caracterizado pelo aborto e como a vivência do cotidiano da especialidade pode contribuir para modificar ou solidificar posicionamentos dos profissionais.

\section{Metodologia}

Os dados empíricos que apoiam as análises e discussóes propostas constituem recorte de uma investigação mais ampla sobre a incorporação da perspectiva de gênero na formação médica e na prática clínico-assistencial de residentes de Medicina de Família e Comunidade e Ginecologia e Obstetrícia de duas universidades públicas de São Paulo. O objetivo do estudo foi analisar a percepção sobre a formação em 
Ginecologia e Obstetrícia e Medicina de Família e Comunidade acerca da temática do aborto. O estudo foi realizado após a aprovação do Comitê de Ética em Pesquisa da instituição proponente (processo CEP. 1.912.088).

A pesquisa seguiu a metodologia qualitativa aplicada à saúde e a produção dos dados empíricos se norteou pela técnica de entrevista em profundidade, devido a sua potencialidade de captar, a partir de um roteiro predefinido flexível, os valores e os sentidos que os sujeitos atribuem às suas experiências pessoais e profissionais ${ }^{12}$. O roteiro construído abordou perguntas amplas sobre as vivências da formação em medicina e as experiências no contexto da residência médica concernente às temáticas de gênero e abortamento, buscando dar voz e liberdade aos participantes da pesquisa na temática central do estudo.

As entrevistas foram realizadas no período de maio a setembro de 2017, após esclarecimento e assinatura do Termo de Consentimento Livre e Esclarecido (TCLE) pelos participantes. A técnica para captação dos sujeitos foi a estratégia de recrutamento em cadeia ou "bola de neve", buscando-se uma amostra não probabilística onde os participantes do estudo indicam outros participantes, até que se atinja o ponto de saturação. A escolha desta estratégia se deveu ao seu custo-benefício e praticidade ${ }^{13}$. Os primeiros participantes foram acessados no âmbito dos dois cursos de Residência citados, por indicação dos coordenadores dos programas de residência das universidades. Como critérios de inclusão, consideraram-se: homens e mulheres, cursando Residência Médica em Medicina de Família e Comunidade e Ginecologia e Obstetrícia, que aceitassem participar do protocolo de investigação pela assinatura do TCLE.

Foram realizadas 13 entrevistas, contando, entre essas, sete profissionais especializados em Ginecologia e Obstetrícia (GO) e seis profissionais especializados em Medicina de Família e Comunidade (MFC). As entrevistas foram realizadas individualmente, em local definido pelos entrevistados, com média de duração de cinquenta minutos e gravadas com permissão dos entrevistados e assinatura do TCLE. Todas as entrevistas foram transcritas na íntegra e, na sequência, foi realizada a verificação da acurácia das transcrições. O número final de entrevistados não foi definido a priori e, sim, durante o trabalho de campo, usando o critério de saturação de falas e significados atribuídos à experiência sobre conteúdos relacionados à perspectiva de gênero na formação médica e ao abortamento no contexto da formação teóricoprática na residência médica ${ }^{14}$.

O quadro 1 mostra a caracterização dos entrevistados. Os nomes foram substituídos pela letra "E” acompanhada de um número, com o intuito de preservar suas identidades. O quadro não omite a faculdade de graduação, por considerarmos importante demonstrar a diversidade entre os entrevistados quanto ao local de formação e métodos de ensino. Conforme o ano de formação de cada um deles expressa, são todos médicos jovens, que ainda vivenciam um processo de construção de seu eu-médico e com lembranças recentes da graduação. 
Quadro 1. Caracterização dos entrevistados

\begin{tabular}{|c|c|c|c|c|c|}
\hline Entrevistado & Sexo & $\begin{array}{c}\text { Faculdade de } \\
\text { Graduação }\end{array}$ & $\begin{array}{c}\text { Ano de } \\
\text { Formação }\end{array}$ & $\begin{array}{l}\text { Faculdade de } \\
\text { Residência }\end{array}$ & Especialidade \\
\hline E1 & Feminino & FAMERP & 2011 & UP1 & $\mathrm{GO}$ \\
\hline E2 & Feminino & FMUSP & 2014 & UP1 & $\mathrm{GO}$ \\
\hline E3 & Feminino & UNILUSSANTOS & 2013 & UP1 & $\mathrm{GO}$ \\
\hline E4 & Feminino & UNIFESP & 2013 & UP2 & $\mathrm{GO}$ \\
\hline E5 & Masculino & UNIFESP & 2014 & UP2 & $\mathrm{GO}$ \\
\hline E6 & Masculino & UNIFESP & 2014 & UP2 & GO \\
\hline E7 & Feminino & UFBA & 2015 & UP1 & $\mathrm{GO}$ \\
\hline E8 & Feminino & UFPR & 2014 & UP1 & MFC \\
\hline E9 & Feminino & FMUSP & 2014 & UP1 & MFC \\
\hline E10 & Feminino & Santa Casa - SP & 2015 & UP1 & MFC \\
\hline E11 & Masculino & UEPA & 2015 & UP1 & MFC \\
\hline E12 & Feminino & PUC Campinas & 2015 & UP1 & MFC \\
\hline E13 & Masculino & PUC Sorocaba & 2015 & UP1 & MFC \\
\hline
\end{tabular}

O processo analítico-interpretativo do material empírico foi realizado por meio da análise de conteúdo temático ${ }^{15}$. $\mathrm{Na}$ análise, focalizamos tanto os temas previstos no roteiro como os emergentes e, para ambos, seguimos quatro etapas no processo de análise: 1. processo de impregnação dos relatos, 2. delimitação dos temas prioritários para análise (temas previstos no roteiro e emergentes ), 3. síntese preliminar dos principais achados; 4 . confrontação dos achados empíricos primários com a literatura relativa aos temas e a fundamentação teórica. Do processo de análise emergiram as seguintes categorias de análise: abordagem da temática na graduação e vivências na residência; diferenciação entre abortamento espontâneo ou induzido e acolhimento na assistência ao processo de abortamento. Os resultados e a discussão destas categorias serão apresentados a seguir.

\section{Resultados e discussão}

\section{Abordagem da temática na graduação e vivências na residência}

Historicamente, o campo médico se volta para a prática como principal meio de transmissão dos saberes, muitas vezes desvalorizando o aprendizado teórico. Quando o tema em questão é ligado ao relacionamento médico-paciente, a vivência prática assume papel relevante e poucas diretrizes político-pedagógicas são formalmente instituídas. Dada a relevância da temática aborto para o campo da saúde das mulheres, as repercussões em termos da saúde física e psíquica, os preconceitos associados e o tabu social envolvendo o tema do abortamento induzido se perpetua no ambiente acadêmico. Em conjunto com diversos outros temas considerados polêmicos (sexualidade, abuso de drogas, violência), a formação dos estudantes de Medicina parece não possibilitar a construção de uma relação médico-paciente na qual haja uma postura empática e um ambiente de acolhimento para abordagem do problema, prejudicando, dessa forma, a visão do paciente como um ser além de sua condição e/ ou 
patologia no momento da consulta. Ao desvalorizar a percepção da inserção social do paciente e desconsiderar suas vulnerabilidades, o cuidado médico deixa de ser centrado na pessoa e valoriza o problema apresentado.

Estudo realizado com estudantes de Medicina de uma universidade particular do estado da Bahia, em $2013^{16}$, evidenciou que a formação relacionada ao tema parece concentrar-se na segunda metade do curso médico, sugerindo uma importância das vivências práticas na formação do graduando. Outro estudo conduzido em $2012 \mathrm{com}$ alunos do 6 o ano do curso de Medicina ${ }^{17}$ obteve que $72,7 \%$ dos alunos consideram insatisfatória a atenção recebida pelo tema durante a graduação, havendo pouca abordagem dos procedimentos necessários para a realização de abortamento. Mesmo para médicos ginecologistas e obstetras, há indicaçóes na literatura de que existem déficits no conhecimento dos procedimentos formais e legais. Assim, em pesquisa realizada por Faúndes ${ }^{18}$, foram identificadas falhas com relação às informações relativas aos documentos necessários para se realizarem os abortamentos legais.

A abordagem da temática do abortamento durante a graduação médica, que sobressai das análises das entrevistas, permite delinear um panorama preocupante. Embora a totalidade dos entrevistados refira presença de aulas sobre o tema, a abordagem teórico-prática nas distintas faculdades onde se graduaram é voltada para questôes legais e biológicas, conduzindo para um momento de tensão durante a prática clínica, de forma dissonante com o previsto na Norma Técnica - Atenção Humanizada ao Abortamento ${ }^{1}$. Foi comentado que, por tratar-se de tema polêmico, poucos docentes estariam dispostos a aprofundar-se no assunto, reconhecendo a dificuldade de discuti-lo. Também foi destacado que a política institucional influencia a quantidade e a qualidade das aulas, conforme observado no excerto de entrevista abaixo:

"Se chegasse uma paciente em risco de vida que precisava fazer um aborto, ela tinha que ser mandada para outro hospital [...]. Porque era católico [a instituição]. Então os residentes não aprendiam a fazer[...] as pessoas não comentavam muito. Eu tive uma aula sobre isso, mas foi só na graduação e ninguém falava sobre o assunto.” (E12, feminino, MFC)

É importante notar que os casos de abortamento legalizado previstos na legislação atual foram corretamente referidos pela totalidade dos entrevistados, que chegaram a mencionar não haver necessidade de registro de boletim de ocorrência para a realização do aborto em casos de abuso sexual e procedimentos necessários para prosseguir com o abortamento nos casos de anencefalia e risco iminente de morte materna. Tal conhecimento pode ser reflexo da valorização do ensino do panorama legal em que toca o tema abortamento e preocupaçóes de ordem ético-profissional. Ainda foi levantada a postura tomada pela equipe da saúde em geral quando confrontada com casos de abortamentos induzidos no país:

"Existe um contrassenso entre a lei e o código de ética médico. Eu sigo o código de ética, até porque eu também não quero me envolver, mas o que a gente aprende é que pela lei você é obrigado a notificar um aborto provocado, e aí uma vez notificado a promotoria poderia processar essa mulher, e você estaria indo contra a lei se não notificar, sabendo que foi um aborto provocado. Mas isso é completamente contra a privacidade da paciente, que te passou a informação em 
consulta, não é algo que ponha a vida de alguém em risco, não vai por a vida dela nem de outros em risco iminente e só nessas situaçóes que você pode quebrar a privacidade, então segundo o código de ética médico, você está errado em quebrar o sigilo. Então eu e a grande maioria dos GOs tomam essa abordagem. Quando a pessoa admite, seja porque você achou algo ou porque elas chegam contando, o que eu faço: explico as complicaçóes, a implicação legal caso ela queira contar para alguém e falo que eu não vou contar, mas eu também não escrevo no prontuário. Porque daí eu me comprometo legalmente se eu escrevo no prontuário, e depois alguém descobrir e processar ela.” (E4, feminino, GO)

Os médicos atuam no limite da legalidade, e podem estar sujeitos à judicialização das suas práticas. $\mathrm{O}$ ato de omissão em prontuário, quando conhecida a indução do abortamento, é encarado como meio de proteção própria e da paciente de possíveis repercussóes legais caso seja levantada a possibilidade de abortamento induzido. Em relação à possibilidade de denúncia do abortamento ilegal por parte da equipe de saúde, a totalidade dos entrevistados compreende que não é seu papel envolver mecanismos judiciais nos casos de processos induzidos de abortamento.

Um aspecto importante refere-se ao fato de as situações de abortamento serem rotineiras para os médicos e, portanto, ser necessário um cuidado para não banalizar o ocorrido na comunicação com a paciente. O tempo e a prática são considerados fatores determinantes para o desenvolvimento desse cuidado pelo residente.

Residentes de MFC, por outro lado, trouxeram o entendimento da autonomia que as mulheres devem ter sobre o próprio corpo, relatando que, quando se deparam com casos de mulheres com gestaçôes indesejadas e que desejam o abortamento, acolhem e informam no atendimento.

"Eu falei assim: 'você tem algumas opções, tem opção disso, opção de clínica e opção de falar que foi abuso' [...] Aí ela 'nossa, nunca achei que iam me falar isso no posto de saúde, se soubesse tinha vindo antes' e eu peguei e falei 'ó, a gente não tá com muito tempo', ela já tava com 16 semanas. 'Vou te dar um tempo pra você pensar e a gente segura o SIS [ficha de abertura de pré natal], [...] se precisar de alguma ajuda, se sangrar, se for fazer isso tenha alguém por perto' aí foi isso, ela usou três vezes Miso e não abortou.” (E8, feminino, $\mathrm{MFC}$ )

Os residentes em MFC que referiram esse tipo de atuação colocaram a informação sobre métodos e serviços como um direito da pessoa, que optava por abortamento e como parte do acolhimento, considerado parte essencial no método clínico utilizado na Atenção Primária à Saúde (APS). Isso demonstra uma atuação cautelosa no contexto da APS, utilizando-se do que a legislação brasileira sobre interrupção da gravidez permite aos profissionais de saúde.

É possível reconhecer que a abordagem do tema aborto durante a graduação foi bastante uniforme entre os residentes, segundo as diversas faculdades, com privilégio dos temas biológicos e legais relacionados ao abortamento. A falta de discussóes com relação ao acolhimento dessas pacientes caracterizou o maior ponto de tensão e divergência entre os residentes das especialidades: enquanto na $G O$ valoriza-se a prática como meio de aprendizado, sem relatos sobre discussóes teóricas, a MFC 
parece valorizar a discussão como forma de uniformizar a abordagem realizada por seus residentes. Disso decorrem momentos de dificuldade na prática clínica, nos quais a falta de preparo específico dos residentes leva ao desconforto na abordagem do tema e ao acolhimento das pacientes.

\section{Diferenciação entre abortamento espontâneo ou induzido}

Quando convidados a refletir sobre diferenças perceptíveis no trato de pacientes que chegam em processos de abortamentos induzidos ou espontâneos, todos os entrevistados afirmaram que tal diferenciação só é relevante em termos médicos quando considerado que abortamentos induzidos podem cursar com maior gama de complicaçóes, como hemorragia e sepse e, consequentemente, requerer realização de maior número de procedimentos. Esses achados são compatíveis com os de Barbosa, Bobato e Mariuti ${ }^{19}$.

"Quando você pega um caso de abortamento provocado, é um pouco complicado. A gente não gosta de pegar aborto provocado hoje em dia. [...] elas se submetem a umas coisas que são muito danosas, e você pegar uma situação dessas traz ansiedade porque você pensa nas mil coisas que podem acontecer, complicaçôes que podem levar e tal e a gente pega muita complicação, úlcera vaginal, estenose da vagina, até histerectomia, que seria o pior de todos. Então assim, é complicado pegar aborto provocado.” (E4, feminino, GO)

Giglio-Jacquemot ${ }^{20}$ e Machin ${ }^{21}$, em estudos sobre atendimentos em urgências e emergências na perspectiva de profissionais de saúde e usuários, observam que algumas categorias de pacientes são tratadas com indiferença ou agressividade, na medida em que a situação que os leva a buscar o serviço é vista como resultado de uma escolha, uma opção. Suas atitudes os levaram a uma situação socialmente reprovável. Ambos os estudos revelam haver cumplicidade nessa desconsideração com algumas categorias de usuários que realizaram atos autoinfligidos (tentativas de suicídio, aborto, abuso de álcool), pois são compartilhados por médicos, enfermeiras, seguranças, usuários.

Embora os entrevistados relatem que não fazem diferenciação das pacientes com base nisso, referem que é perceptível um trato diferenciado por parte da equipe de Ginecologia e Obstetrícia em geral, tendo sido a equipe da enfermagem e médicos mais velhos mencionados especificamente.

"Não é como uma paciente que chegou em abortamento espontâneo, e você faz todo aquele acolhimento, explica tudo o que está acontecendo. Porque realmente as causas são diferentes né. Uma estava esperando que aquela gestação continuasse, e abortou, e a outra estava esperando que a gestação não continuasse e interviu para que abortasse. Então as motivaçóes e sentimentos das pacientes são diferentes, não tem como tratar de forma igual.” (E6, masculino, GO)

Foi observado que, na maioria dos casos, as mulheres em processo de abortamento ativo não detalham que tenham induzido ${ }^{22}$. Quando questionados sobre o que imaginam que seria a causa desse modo de agir, muitos referem um possível medo de 
julgamentos, receio de consequências judiciais, ou, ainda, arrependimento por parte das mulheres. Além disso, pudemos perceber uma distinção clara nos relatos acerca dos entrevistados sobre os processos de acolhimento das mulheres que induziram o abortamento, a partir do desconforto que os entrevistados referem para a abordagem dessas mulheres.

A referência ao julgamento por parte da equipe de saúde levantou vários relatos sobre os olhares acusadores e as conversas entre membros da equipe do que propriamente interaçóes desrespeitosas diretas da equipe com as pacientes. Mas, houve também relatos de situaçôes de exposição indireta da paciente a contextos potencialmente causadores de sofrimento psicológico. As diferenças de tratamento para com pacientes que induziram o abortamento e as que o tiveram espontaneamente foi referida pelos residentes de MFC como percebida seja na graduação, seja durante estágios específicos na residência.

"A pior possível. Eu acho que não se acolhe da maneira correta, não se trabalha comunicação não violenta e a mulher é absolutamente revirada e não se respeita o momento que ela tá passando. [...] Se há um indício de que isso seja provocado, isso é ainda pior, porque aí é mais agressividade, mais violência.” (E13, masculino, MFC)

Contudo, quando questionados sobre a própria equipe formada por médicos de família e outros profissionais de saúde com atuação na APS, os residentes de MFC relataram uma postura de acolhimento e maior empatia, que relacionaram com a frequência de situaçôes semelhantes atendidas nos serviços de sua especialidade.

\section{Acolhimento na assistência ao processo de abortamento}

Preconizado na Política Nacional de Humanização ${ }^{23}$, o processo de acolhimento se baseia em uma escuta qualificada e acesso às tecnologias necessárias. É uma das principais diretrizes das práticas de cuidado em saúde, e se processa segundo a lógica denominada por Neves e Heckert ${ }^{22}$ como intersubjetiva-relacional, a qual diz respeito à compreensão do acolhimento como relação com o outro, construção de vínculos interpessoais a partir de uma escuta solidária e atenta aos sofrimentos na/ e pela abertura do exercício clínico ao plano coletivo e relacional. As mençóes dos entrevistados sobre o acolhimento das mulheres que abortam foram referidas às relaçóes que as pacientes e equipes estabelecem, e estas foram percebidas como deficitárias, particularmente na equipe de GO. Fatores como grande fluxo de pacientes, pouco tempo para atendimento e os próprios medos da mulher que busca ajuda após abortamento autoinduzido interagem causando prejuízo ao relacionamento médicopaciente, além de possíveis constrangimentos para a mulher que busca o serviço. A humanização do serviço também é contemplada nesse momento de pensar organização de fluxo e gerenciamento de recursos, de modo a garantir o acesso de população vulnerável e seu atendimento digno. A deficiência na comunicação perpassa desde a organização estrutural do serviço ao preconceito dos profissionais no exercício dos atendimentos. 
O não estabelecimento de uma relação adequada com as pacientes é um fator que limita o cuidado segundo os entrevistados. Foi referido que trabalhar nesse acolhimento das pacientes poderia ajudar no planejamento de assistência, para entender o que levou a mulher a provocar o abortamento, os caminhos que foram seguidos. Além disso, como forma de otimizar o relacionamento com as pacientes, sugerem que poderiam ser feitas certas mudanças no fluxo dos atendimentos às mulheres, com um acompanhamento longitudinal com um profissional que conheça a história a fundo, em vez de a paciente estar repetidamente exposta a julgamentos pelos novos profissionais com os quais entra em contato.

Considerando a estruturação do sistema de saúde e suas consequências para o acolhimento dessas mulheres, foi discutido o papel deste na limitação do estabelecimento de uma relação com as pacientes. Um sistema no qual o tempo disponível para cada atendimento é reduzido torna difícil abordar questóes delicadas como o abortamento. Ademais, é raro que haja um acompanhamento da mulher por um profissional fixo durante o trajeto pelo serviço, conforme previamente considerado por entrevistados. A vulnerabilidade da mulher aos julgamentos de diversos profissionais, repetidas vezes, afeta não só o cuidado dispensado no momento, mas também a confiabilidade futura no serviço de saúde e disposição em contatá-lo quando necessário.

De modo geral, todos os entrevistados compreendem a importância do acolhimento adequado das pacientes, o que também é observado em outros estudos ${ }^{19}$. Entretanto, houve diferenças entre os residentes da GO e MFC quanto a carga teórico-prática do tema. Os residentes da MFC referem um acompanhamento dos casos de modo mais próximo aos médicos assistentes, que abordam questóes relacionadas ao tema no contexto das aulas. Isso parece ajudar na constituição de uma orientação mais uniforme quanto à abordagem das pacientes pelos médicos quando estes se deparam com questôes mais polêmicas quando surgem dúvidas sobre os procedimentos técnicos.

A abordagem de questões de gênero durante a formação também foi um dos fatores que contribuíram para fazer com que os residentes em MFC se vissem mais preparados para lidar com situaçóes de abortamento autoinduzido comparativamente aos profissionais de GO. Neste quesito, a visão do profissional sobre a mulher que abortou, seus motivos e as possíveis consequências dessa ação também foram abordados.

"Eu sou uma pessoa que não consigo fazer, por restriçóes religiosas [...] eu não tenho uma posição de achar que tenho uma verdade absoluta, acho que eu só vou saber isso se eu estiver numa situação, por exemplo, uma cardiopata que tem um filho e se ela abortar é uma chance de continuar sendo mãe do filho que ela tem, se ela não abortar provavelmente vai morrer e deixar esse bebê órfão, $o$ que é certo? Eu não sei, nesse momento eu só sei que eu não consigo fazer esse aborto terapêutico. Agora, se é errado essa mulher fazer, não sei [...] ela vai deixar o menino dela órfẫo [...]. Principalmente isso de não querer, para mim é muito complicado. Eu tenho dúvida sobre o aborto naquelas situaçôes terapêuticas que eu te falei, agora não consigo. Tem toda essa questão de o corpo é meu, mas tem o corpo de outra pessoa aí dentro, eu acho que já é outra pessoa sabe, eu fico pensando assim, a gente é contra a sentença de morte, mas tudo bem matar um bebê? [...] Não é simples, eu não acho que é uma coisa que a pessoa acordou e 'eu vou fazer um aborto hoje' [...] nunca é simples.” (E1, feminino, GO) 
Os motivos que conduzem uma mulher a buscar abortamento são vários, e se interceptam em âmbitos social, individual e econômico. As trajetórias dessas mulheres ${ }^{24}$ envolvem: diversos agentes, possibilidade de acesso ao serviço de saúde, $e$, ainda, aspectos relacionados à gênero e sexualidade que emergiram quando os entrevistados se debruçaram em reflexóes quanto às consequências da gravidez nos relacionamentos da mulher e a presença, ou não, do parceiro no momento da decisão pelo aborto: "Quem está grávida é a mulher, quem foi irresponsável foi a mulher, não foi uma opção do homem. E é isso que a gente vê na prática. "Ah, e o companheiro?" “não quer”. E é simples, não quer” (E1, feminino, GO). Tal fala demonstra como o enraizamento dos papéis de gênero na sociedade pode ter efeitos com repercussóes sociais e da saúde intensas, pois, no caso de uma mulher cujo companheiro a abandona durante a gestação, num país em que o abortamento é ilegal e perigoso, a repercussão dessa gravidez na vida futura de ambas, a mulher e a criança, pode ser significativa.

Foi importante perceber que os médicos também estão cientes do seu direito de objeção de consciência, para casos em que não haja risco iminente de morte e que outros profissionais capacitados possam realizar a assistência. Porém, há situações que derivam de julgamento pela moral religiosa, trazendo à tona a necessidade de melhor preparar os médicos, evitando que suas crenças pessoais interfiram de forma prejudicial no relacionamento com as pacientes sob sua responsabilidade.

Contudo, mesmo com a legislação restritiva, a realidade da situação de abortamentos induzidos no Brasil tem dimensão significativa para a saúde pública, e o contato dos médicos com essa realidade, se não frequente, ocorrerá certamente em algum momento. Sobre essa realidade, foi comentado:

"Porque a gente sabe que no Brasil quem quer abortar aborta, mas quem complica o abortamento é quem é pobre, não tem dinheiro para pagar uma clínica da abortamento, que a gente sabe que tem aos montes por aí. Quem não tem esse dinheiro para fazer um abortamento um pouco mais seguro, apesar de ainda ilegal, é quem aborta com agulha de crochê, quem aborta com sonda, cabides, esses abortamentos são os que complicam. Abortamento em clínica de aborto, com comprimido que se acha na Praça da Sé, esses se sucedem um pouco mais tranquilamente, e aí não chega para nós.” (E6, masculino, GO)

Nesse sentido, os residentes de MFC adotaram uma postura ativa quando a legislação foi mencionada, posicionando-se favoráveis à legalização do aborto. A argumentação utilizada para embasar tal posicionamento perpassou tanto por questóes envolvendo o direito da mulher de decidir sobre seu próprio corpo, num entendimento de que ela teria autonomia de decisão que se sobrepóe aos direitos de qualquer outra pessoa sobre o concepto, e pelas evidências em saúde pública, que indicam maiores taxas de morbimortalidade entre as mulheres que induzem o abortamento.

"A questão do gênero, de não deixar a mulher ser dona do próprio corpo e achar que ela tem esse instinto natural de parir e que toda mulher tem que amar esse período da gestação. E quando a gente começa a desconstruir esse conceito e problematizar a questão de gênero, é muito mais fácil resolver. O que eu quero 
dizer é que assim eu acho que a Medicina de Família é diferente. Não é porque a gente discute o abortamento, eu acho que é porque é trabalhada a questão da autonomia da mulher, de ser dona do próprio corpo, das próprias decisóes, de modo que eu não preciso discutir qual que é a minha opinião sobre aborto, porque é muito óbvio.” (E13, masculino, MFC)

Entre os médicos de ambas especialidades, há concordância em relação à questão da percepção de que a ilegalidade do abortamento tem pouco impacto real sobre o curso de ação quando uma paciente decide interromper uma gestação, agindo apenas como fator de risco para aquelas mulheres que não dispóem de acesso a meios seguros de realizá-lo. Embora não haja relação direta entre a legalização do aborto e acesso ao procedimento seguro e redução de suas taxas, também não há com o aumento explosivo comumente alegado. O grande impacto na redução das gravidezes indesejadas advém de uma política de educação sexual e planejamento familiar, que permita evitar gestações não planejadas ${ }^{25}$.

\section{Considerações finais}

A formação teórica durante a faculdade de Medicina no que tange ao tema abortamento indica estar ainda pautada no âmbito biológico e legal, relegando ao "bom senso" e "tato" pessoais a busca de um vínculo com a paciente que chega fragilizada. Nas residências de GO e MFC, a presença de aulas teóricas e discussóes voltadas a gênero, sexualidade e feminilidade parecem contribuir para uniformizar a prática clínica.

A partir dos relatos dos entrevistados, foi perceptível que os atendimentos prestados às mulheres em abortamento privilegiam a dimensão técnica. A ênfase do cuidado, de forma geral, parece concentrar-se na recuperação física e reprodutiva, mesmo quando projetam que é importante considerar os aspectos psicológicos e de estímulo à autonomia feminina sobre o próprio corpo. Os entrevistados se expressaram sobre os sofrimentos acarretados pelo aborto, espontâneo ou induzido, e entendem o cuidado e o acolhimento como o ato de proferir palavras de conforto às pacientes, mesmo que sem questionamentos sobre a etiologia do aborto. A maioria demonstrou dificuldade de considerar os aspectos legais nos casos de abortamento induzido, sobretudo por estarem protegidos pelo código de ética profissional quanto ao sigilo das informaçóes.

Ao refletirem sobre a formação teórica e as experiências práticas no contexto das residências, se posicionaram, desde a perspectiva de saúde pública, em prol da mudança na abordagem do aborto, o que poderia elucidar momentos de interferência que evitassem a gravidez indesejada, em primeiro lugar, ou que habilitassem a mulher a tomar decisóes quanto ao futuro - ou não - da gestação.

Nesse sentido, o conhecimento clínico, o desenvolvimento de habilidades e técnicas, especialmente a partir da maior inserção da abordagem conceitual de gênero na formação na graduação e na residência, além do amadurecimento de atitudes pessoais, éticas e profissionais, se revelam elementos fundamentais para a formação médica e o exercício do cuidado integral às mulheres em processo de abortamento. 


\section{Contribuições dos autores}

Todas as autoras participaram ativamente de todas as etapas de elaboração do manuscrito.

\section{Agradecimentos}

As autoras agradecem ao Conselho Nacional de Desenvolvimento Científico e

Tecnológico (CNPq) que, por meio das bolsas de iniciação científica das graduandas em Medicina Ana Luísa Smith Rocha e Maria Renata Mencacci Costa, tornaram este estudo possível.

\section{Direitos autorais}

Este artigo está licenciado sob a Licença Internacional Creative Commons 4.0, tipo BY (https://creativecommons.org/licenses/by/4.0/deed.pt_BR).

\section{Referências}

1. Brasil. Ministério da Saúde. Departamento de Açôes Programáticas Estratégicas. Atenção humanizada ao abortamento: norma técnica. 2a ed. Brasília: Ministério da Saúde; 2011.

2. Organização Mundial da Saúde. Abortamento seguro: orientação técnica e de políticas para sistemas da saúde. 2a ed. Genebra: OMS; 2013.

3. Sedgh G, Bearak J, Singh S, Bankole A, Popinchalk A, Ganatra B, et al. Abortion incidence between 1990 and 2014: global, regional, and subregional levels and trends. Lancet. 2016; 388(16):258-67.

4. Diniz D, Medeiros M, Madeiro A. Pesquisa nacional de aborto 2016. Cienc Saude Colet. 2017; 22(2):653-60.

5. Silveira P, McCallum C, Menezes G. Experiências de abortos provocados em clínicas privadas no Nordeste brasileiro. Cad Saude Publica. 2016; 32(2):e00004815.

6. Monteiro GFM, Adesse L, Drezett J. Atualização das estimativas da magnitude do aborto induzido, taxas por mil mulheres e razóes por 100 nascimentos vivos do aborto induzido por faixa etária e grandes regióes. Brasil, 1995 a 2013. Reprod Clim. 2015; 30(1):11-8.

7. Diniz D, Medeiros M. Aborto no Brasil: uma pesquisa domiciliar com técnica de urna. Cienc Saude Colet. 2010; 15 Suppl 1:959-66.

8. Brasil. Ministério da Educação. Diretrizes curriculares nacionais [Internet]. Brasília: MEC; 2001 [citado 26 Jun 2018]. Disponível em: http://portal.mec.gov.br/cne/ arquivos/pdf/2001/pces1133_01.pdf

9. Verdonk P, Benschop YWM, De Haes HCJM, Lago-Janssen TL. From gender bias to gender awareness in medical education. Adv Health Sci Educ Theory Pract. 2009; 14(1):135-52. doi: https://dx.doi.org/10.1007/s10459-008-9100-z.

10. Bleakley A. Gender matters in medical education. Med Educ. 2013; 47:59-70. 
11. Bickel J. Gender equity in undergraduate medical education: a status report. J Womens Health Gend Based Med. 2001; 10(3):261-70.

12. Becker H. Métodos de pesquisa em ciências sociais. São Paulo: Hucitec;1994.

13. Dewes J. Amostragem em bola de neve e respondent-driven sampling: uma descrição dos métodos [Trabalho de Conclusão de Curso] [Internet]. Rio Grande do Sul: Universidade Federal do Rio Grande do Sul; 2013 [citado 26 Jun 2018]. Disponível em http://www.lume.ufrgs.br/handle/10183/93246

14. Fontanella BJB, Ricas J, Turato ER. Amostragem por saturação em pesquisas qualitativas em saúde: contribuiçôes teóricas. Cad Saude Publica. 2008; 24(1):17-27.

15. Silverman D. Interpretação de dados qualitativos. Métodos para análise de entrevistas, textos e interaçôes. Porto Alegre: Artmed; 2009.

16. Darze OISP, Azevedo BKG. Competências adquiridas durante a formação médica e as opiniões e atitudes sobre o aborto. Rev Bras Ginecol Obstet. 2014; 36(1):5-9.

17. Almeida M, Amorim F, Barbosa Í, Dias A, Morita I. Legislação brasileira relativa ao aborto: o conhecimento na formação médica. Rev Bras Educ Med. 2012; 36(2):243-8.

18. Faundes A, Simoneti R, Duarte G, Andalaft-Neto J. Factors associated to knowledge and opinion of gynecologists and obstetricians about the Brazilian legislation on abortion. Rev Bras Epidemiol. 2007; 10(1):6-18.

19. Barbosa ASSF, Bobato JAC, Mariutti MG. Representação dos profissionais da saúde pública sobre o aborto e as formas de cuidado e acolhimento. Rev SPAGEST (Ribeirão Preto). 2012; 13(2):44-55.

20. Giglio-Jacquemot A. Urgências e emergências em saúde: perspectivas de profissionais e usuários. Rio de Janeiro: FIOCRUZ; 2005.

21. Machin R. Nem doente, nem vítima: o atendimento às "lesóes autoprovocadas" nas emergências. Cienc Saude Colet. 2009; 14(5):1741-50.

22. Neves AC, Coelho Heckert AL. Micropolítica do processo de acolhimento em saúde. Estud Pesqui Psicol. 2010; 10(1):151-68.

23. Brasil. Ministério da Saúde. Secretaria de Atenção à Saúde. Núcleo Técnico da Política Nacional de Humanização. Humaniza SUS: documento base para gestores e trabalhadores do SUS. 3a ed. Brasília: Ministério da Saúde; 2006.

24. Coast E, Norris A, Moore AM, Freeman E. Trajectories of women's abortion-related care: a conceptual framework. Soc Sci Med. 2018; 200:199-210.

25. Faundes A, Shah IH. Evidence supporting broader access to safe legal abortion. Int $J$ Gynecol Obstet. 2015; 131 Suppl 1:56-9. 
Abortion is a major public health issue that cuts across various specialities. This study focused on abortion care and its relatioship with the training received in Gynecology and Obstetrics and Family and Community Medicine by residents of two public Colleges in Sao Paulo. A qualitative research design was adopted consisting of the administration of in-depth interviews with 13 residents. The obstetrics and gynaecology residents reported that they relied on practical experience to provide abortion care, while the family and community medicine residents recounted that they discussed the theme and its connection with gender isssues. Clinical knowledge, the devlopment of skills and techniques, and adopting a gender-sensitive approach in training were revealed to be vital components of comprehensive abortion care.

Keywords: Medical education. Abortion. Obstetrics and gynaecology. Family and community medicine. Gender.

El aborto es un tema importante bajo la perspectiva de la salud pública y está presente en la práctica de diversas especialidades. Enfocamos la asistencia a procesos de aborto y su relación con la formación recibida en Ginecología y Obstetricia (GO) y Medicina de Familia y Comunidad (MFC), de residentes de dos facultades públicas de São Paulo. El estudio siguió la metodología cualitativa y la producción de los datos empíricos se rigió por la técnica de entrevista en profundidad (13 residentes). Los residentes de GO relatan que se rigen por las experiencias prácticas para la dirección de los casos de aborto. Los residentes de MFC relatan discusiones sobre el tema y sus vínculos con cuestiones de género. El conocimiento clínico, el desarrollo de habilidades y técnicas y la mayor inserción del abordaje de género en la formación se revelan como fundamentales para el ejercicio del cuidado integral a las mujeres en proceso de aborto.

Palabras claves Formación médica. Aborto. Ginecología y obstetricia. Medicina de familia y comunidad. Género. 